\title{
Smart Demand for Improving Short-term Voltage Control on Distribution Networks
}

\author{
Garcia-Valle, Rodrigo; P. Da Silva, Luiz C.; Xu, Zhao; Østergaard, Jacob
}

Published in:

IET Generation Transmission and Distribution

Link to article, DOI:

10.1049/iet-gtd.2008.0621

Publication date:

2009

Document Version

Publisher's PDF, also known as Version of record

Link back to DTU Orbit

Citation (APA):

Garcia-Valle, R., P. Da Silva, L. C., Xu, Z., \& Østergaard, J. (2009). Smart Demand for Improving Short-term Voltage Control on Distribution Networks. IET Generation Transmission and Distribution, 3(8), 724-732. https://doi.org/10.1049/iet-gtd.2008.0621

\section{General rights}

Copyright and moral rights for the publications made accessible in the public portal are retained by the authors and/or other copyright owners and it is a condition of accessing publications that users recognise and abide by the legal requirements associated with these rights.

- Users may download and print one copy of any publication from the public portal for the purpose of private study or research.

- You may not further distribute the material or use it for any profit-making activity or commercial gain

- You may freely distribute the URL identifying the publication in the public portal 


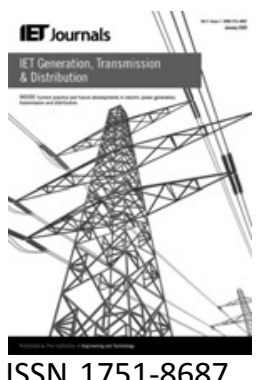

\title{
Smart demand for improving short-term voltage control on distribution networks
}

\author{
$\begin{array}{llll}\text { R. Garcia-Valle } & \text { L.C.P. da Silva } & \text { Z. } X u^{1} & \text { J. Østergaard }\end{array}$ \\ ${ }^{1}$ Centre for Electric Technology, Department of Electrical Engineering, Technical University of Denmark, 2800 Kgs. Lyngby, \\ Denmark \\ ${ }^{2}$ School of Electrical and Computer Engineering, University of Campinas, Campinas-SP, CP 6101, CEP 13083-852, Brazil \\ E-mail: rgv@elektro.dtu.dk
}

\begin{abstract}
Smart grids must involve active roles from end users in order to be truly smart. The energy consumption has to be done in a flexible and intelligent manner, in accordance with the current conditions of the power system. Moreover, with the advent of dispersed and renewable generation, increasing customer integration to aid power system performance is almost inevitable. This study introduces a new type of smart demand side technology, denoted demand as voltage controlled reserve (DVR), to improve short-term voltage control, where customers are expected to play a more dynamic role to improve voltage control. The technology can be provided by thermostatically controlled loads as well as other types of load. This technology is proven to be effective in case of distribution systems with a large composition of induction motors, where the voltage presents a slow recovery characteristic due to deceleration of the motors during faults. This study presents detailed models, discussion and simulation tests to demonstrate the technical viability and effectiveness of the DVR technology for short-term voltage control.
\end{abstract}

\section{Introduction}

Voltage stability and control are increasingly becoming a limiting factor in the planning and operation of power systems. During steady-state operation, bus voltages must be controlled within a specified range. A suitable voltage and reactive power control allows one to obtain important benefits in power system operation, such as reduction of voltage gradients and energy loss in electricity transportation, efficient transmission capacity utilisation and increase of stability margins. By applying various control equipments and methods, the voltage control objectives in the transmission system can be achieved by some controllers working on the basis of injecting a series voltage while others inject a shunt reactive current at the point of connection with the power system. Following a disturbance, changes in the system voltage take place and restoration to the reference values depends very much on the dynamic response of excitation systems and other voltage controllers. Usually voltage control is performed by adjusting the field current of generators, continuous reactive power injection provided by static voltage compensation, by switching the action of capacitors and reactors, or by onload tap changers or voltage regulators installed at strategic sites of the transmission and distribution systems. Nevertheless, these equipments do not adequately support short-term voltage control because of faults on transmission or distribution systems. Short-term voltage control has a relatively short duration, a few seconds, so there is no time to switch mechanical devices $[1,2]$. In addition, the large concentration of induction motors (IMs) and distributed generation in some actual power systems causes an impact on short-term voltage stability, making it a more complex issue to control [3-7]. Adequate short-term voltage control will reduce the activation of protective relays and reduce the reactive power injection from the generation side; hence consequence there will be less power losses on the distribution and transmission network [8-10].

To assist in this task, distributed clients could aid at a low cost and without influencing the normal operation of the loads. Many electric appliances can be flexibly disconnected from the network for a short period without significant impacts on their internal processes or delivered services. 
This is the case for thermal loads, such as freezers, refrigerators, air conditioners, water heaters, heat pumps etc., since they indeed have a certain capacity of energy storage in the form of thermal energy, actually with a high thermal inertia of many minutes or hours [11]. This idea has been investigated to improve frequency control (demand as frequency controlled reserve, DFR), where the thermal loads could provide fast active power reserve, in Denmark, UK and USA [12-14]; however, it has never been studied to provide short-term voltage control. It has been demonstrated that a very small, effective and cheap micro-controller with the capability of sensing the frequency supplied by the network can be developed and added to the conventional cyclic control of thermal loads, in order to disconnect the supplies in case of abnormal frequency and reconnect it in case of recovery to normal values [12-14]. Many regulatory, political and economical aspects need to be clarified in order to allow the spread application of this technology; however, its benefits and technical viability have been fully demonstrated [12-14].

The objective of this paper is to demonstrate that shortterm voltage control can be improved through the application of demand voltage controlled reserve (VCR) technology. This means that a DVR device with the capability of sensing the voltage magnitude supplied by the network could also be added to the cyclic control of thermal loads, for example to disconnect supplies in case of voltage drop or voltage rise. The disconnection of supplies for few minutes would lead to an insignificant variation of their temperature, but can be fundamental to avoid the trip of IMs and other sensitive loads, and even to avoid the transmission of additional reactive power from the generation area. It is important to reinforce that DVR is not an undervoltage load shedding action as proposed in [15], but a demand side smart voltage control technique. Also, due to the high thermal inertia, there would be no prejudice to the normal operation and processes of the supplies.

It is worth emphasising that DVR technology can be integrated with DFR technology, making use of the same micro-processor, resulting in a multi-functional device on the demand side, in order to improve the control of both the voltage and frequency magnitudes. DVR technology can still be extended to improve long-term voltage control, but these topics will be addressed in future research activity.

\section{Impacts of IMs on short-term voltage recovery}

IMs represent a very important portion of the total load of modern distribution systems, occasionally encompassing $60-70 \%$ of the total demand $[1,16]$. It is well known that the large penetration of IMs may produce an impact on voltage at distribution systems after a fault is cleared; this action is mainly related to the deceleration of motors during the fault and to their large demand for active and reactive power after the fault is cleared [17, 18]. Voltage drops can lead to customer interruptions and equipment damage $[1,2]$, and furthermore a non-adequate short-term voltage control has secondary effects such as activation of protective relays, electric load disruption, motor stalling etc. $[19,20]$. In addition, the increased number of voltagesensitive loads and the requirements to improve voltage magnitude impose more strict criteria for its control after severe disturbances. Many sensitive loads may have very constrained settings of protective equipment.

Fig. 1 shows the bus voltage magnitude for a system with considerable penetration of IM loading during a voltage drop due to a three-phase fault with a duration of $400 \mathrm{~ms}$ on the distribution feeder. As observed, the voltage drop remains for more than $3 \mathrm{~s}$ after the fault is cleared (voltage magnitude lower than 0.95 p.u.).

This analysis confirms that the voltage drop may exhibit slow recovery characteristics, mostly due to the deceleration of IM during this period, as shown in Fig. 2a. During the faulted period, the electrical torque drastically decreases with the square of voltage whereas the mechanical load decreases at a lower rate according to the speed. As a result, IMs will slow down. After the fault is cleared, the motors will demand a high inrush current and a large amount of reactive power to rebuild the air gap flux and to reaccelerate to normal speed, as shown in Fig. $2 b$. The operation with low power factor during the re-accelerating process may slow down the voltage recovery, which can last for several seconds [1]. The main idea investigated in this paper is to allow some non-essential loads to disconnect, in order to improve voltage recovery and re-acceleration of IM after faults. Disconnection of the loads as well as reconnection after recovery of system voltage to normal level could be done by using DVR technology.

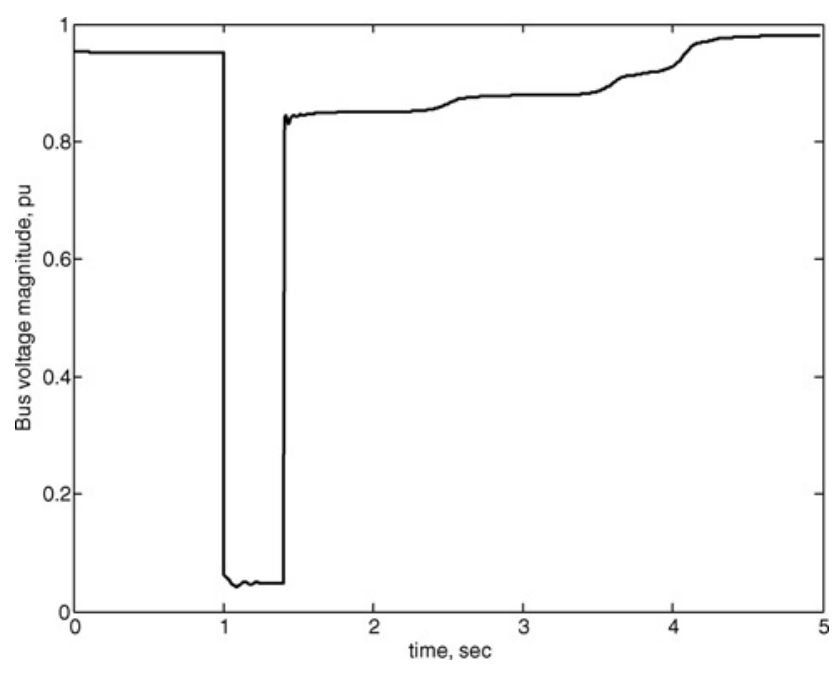

Figure 1 Bus voltage magnitude during voltage drop 

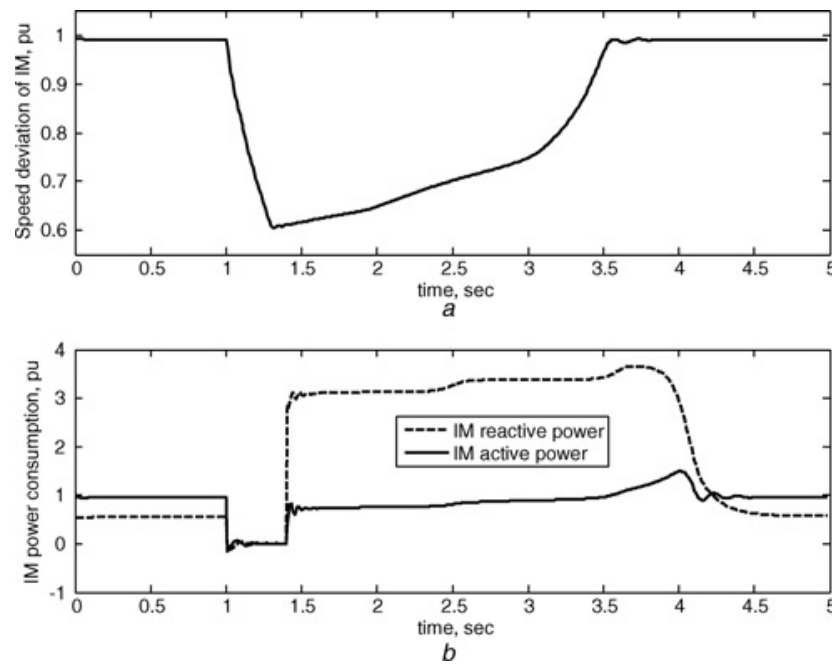

Figure 2 Induction motor behaviour during voltage drop

a Speed deviation

$b$ Active and reactive power consumption

\section{DVR design and modelling}

DVR compatible loads mainly include thermostatically controlled loads such as heat pumps, air conditioners and refrigerators, which can be switched flexibly. Short interruptions will not have big impacts on customers and appliances. The control strategy is basically the switching action of loads in response to voltage magnitude variations, for example 0.94 p.u. at the connecting point, for a short period of time. Time delays for dis/reconnection are also considered and they can be introduced deliberately for different technical considerations, such as dealing with measurement noise, avoiding simultaneous reconnection and releasing compressor internal pressure $[11,12]$. The DVR is certainly applicable for long-term voltage control, but it is not the focus of this paper.

\subsection{DVR control scheme}

The DVR control scheme has three stages as depicted in Fig. 3:

(a) Voltage measurement: the scheme starts measuring the voltage at a time step of $20 \mathrm{~ms}$. A moving average filter with a length of, for example, $200 \mathrm{~ms}$ can be used to remove measurement noise. Either a software or a hardware filter can be implemented.

(b) Disconnection: the scheme continuously compares the voltage with the disconnection criteria and turns off the appliances according to control logic.

(c) Reconnection: after disconnection, the scheme continues to measure and compare the voltage with the reconnection criteria. If satisfied, the appliances will be reconnected back to the grid.

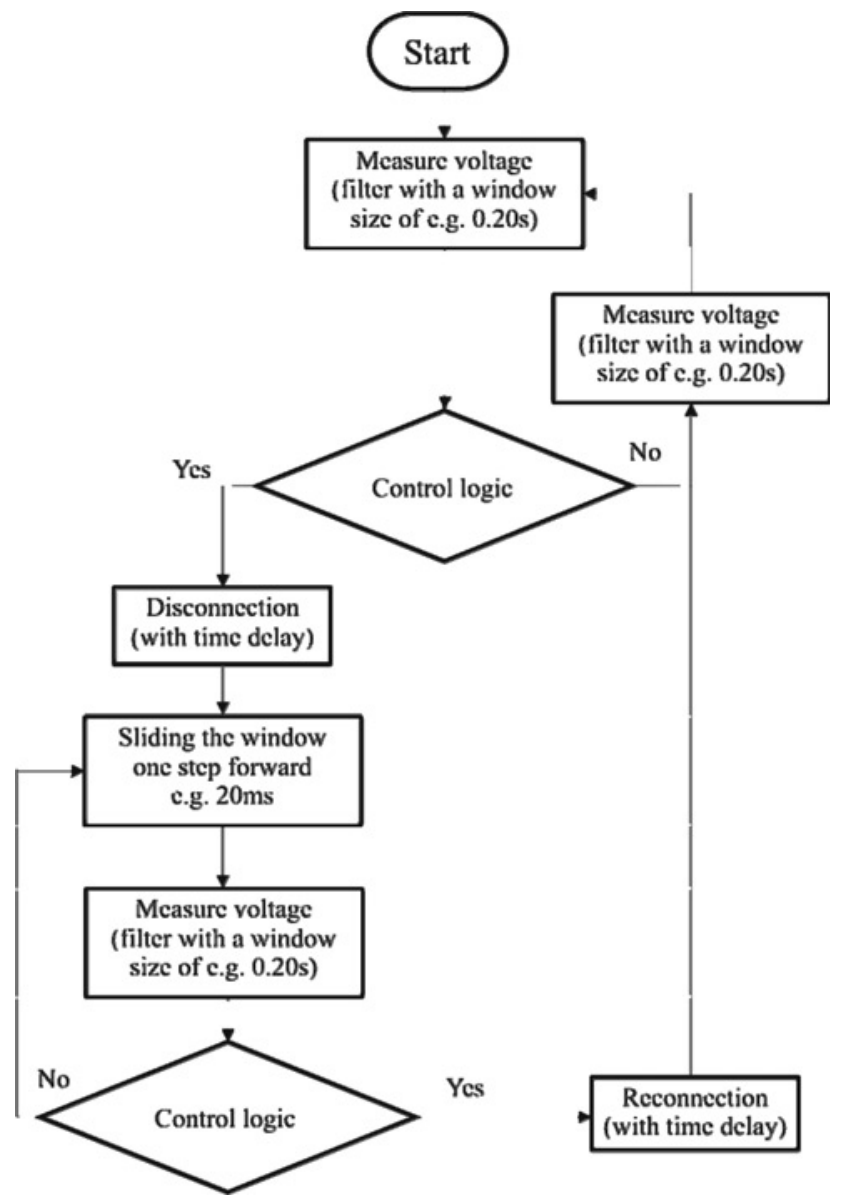

Figure 3 Block diagram for dis/reconnection of the DVR control scheme

Two types of control logics are developed. Depending on the control logic, the dis/reconnection action can be conducted in a direct or indirect way, and the control can be implemented externally as a control box or integrated within the appliances.

\subsection{DVR control logics}

The type I DVR model possesses an external control that disconnects and reconnects electric appliances such as heat pumps or air conditioners when the system voltage falls and recovers, respectively. The reconnection set point $V_{\text {on }}$ should be equal to or higher than the disconnection set point $V_{\text {off }}$ for a hysteresis that can prevent oscillatory behaviours and consequently wear out the appliances, as shown in Fig. 4.

In summary, type I control consists of the following:

- Disconnection criteria - to trip loads for voltage magnitude, for example $V_{\text {off }}<0.94$ p.u., considering a certain time delay.

- Reconnection criteria - to reconnect loads when system voltage recovers with a margin above the tripping set point, for example $V_{\text {on }}>0.95$ p.u., considering a certain time delay. 


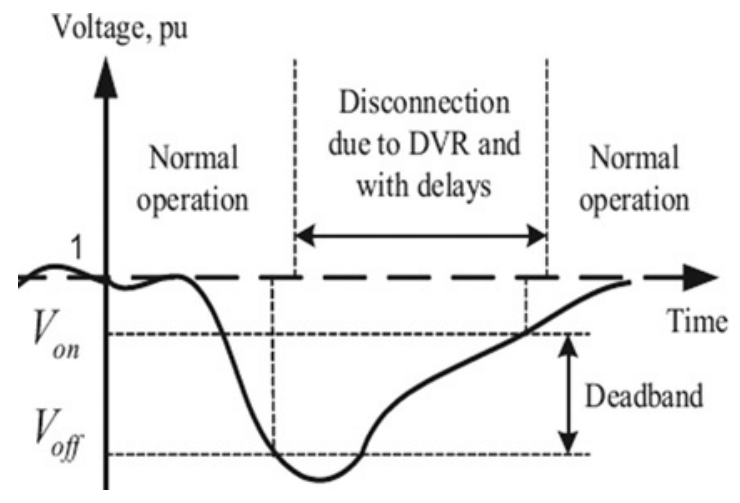

Figure 4 Illustration of DVR type I control

The disconnection set point can be designed according to [21]. In addition, to prevent overactivation of reserve from the DVR model, it is necessary to design the disconnection set points for such appliances to be different from each other. If the set points of many appliances are randomly distributed over a small range, for example 0.90-0.95 p.u., the support from DVR can be activated smoothly and proportionally as required by power systems [22-25]. A similar action can be used to avoid simultaneous reconnection of the loads. Finally, type I control logic can include forced reconnection after a certain time to avoid impact on the delivered service of the appliance to the consumer.

Type II DVR includes an integrated control, specially designed for thermostatically controlled loads with cyclic on/off operations, such as heat pumps, air conditioners, refrigerators etc. In contrast to the type I DVR model, which has a direct switching action to control loads according to system voltage magnitude, the temperature set points of such loads are controlled according to the voltage magnitude. A linear relationship between temperature set points and system voltage can be used for air conditioners and other heating and cooling appliances, described by

$$
\begin{aligned}
& T_{\text {high }}=T_{\text {high }}^{\text {normal }}-k f\left(V-V_{0}\right) \\
& T_{\text {low }}=T_{\text {low }}^{\text {normal }}-k f\left(V-V_{0}\right)
\end{aligned}
$$

where $T_{\text {high }}$ and $T_{\text {low }}$ are the nominal high- and lowtemperature set points, $V_{0}$ is the system nominal voltage, $V$ is the actual system voltage and $k f>0$ is the coefficient of voltage change in ${ }^{\circ} \mathrm{C} /$ volt.

\subsection{Model implementation}

Type I DVR has been implemented using DIgSILENT Power Factory Software. One DVR model includes up to 100 electric appliances, that is, thermal loads, for which the thermodynamics of the individual unit is explicitly modelled as

$$
C \frac{\mathrm{d} T}{\mathrm{~d} t}+G\left(T-T_{\mathrm{a}}\right)+P_{\text {disturbance }}=-w \times P
$$

where $C$ is the heat capacity of the cooling mass, $G$ is the thermal conductance between cooled and non-cooled mass, $P$ is the appliance power, $T$ is the temperature of the cooled mass, $T_{\mathrm{a}}$ is the environment temperature and $w=1$ during unit 'on' stage and $w=0$ during 'off' stage, that is the hysteresis is modelled. $P_{\text {disturbance }}$ representing external disturbance due to the action of an open/closed door is modelled as white noise. The parameters in (3), including $C, G$ and $P$, were modelled using normal distribution to account for diversity, see Table 1 .

To reduce the complexity of modelling work, several simplifications were made. The appliance power $P$ is considered to be constant without voltage and frequency dependence. The reactive consumption of appliances is considered the same as real consumption. Common temperature set points are used for all appliances in the aggregated DVR model. These simplifications do not significantly reduce the validity of the final results, and further improvement of the developed model will be made in our future research.

DVR model initialisation randomly assigns the temperatures of individual units uniformly distributed between $\left(T_{\text {low }}<T<T_{\text {high }}\right)$. A separate parameter is used to control the percentage of appliances with 'on' initial action.

Fig. 5 shows the active power consumption of the DVR model and the voltage profile at the connected bus for a simulation period of $5 \mathrm{~min}$. As observed, the voltage magnitude varies in accordance with the random behaviour of the DVR model. The average active and reactive power consumption of the DVR model during this simulation time is around $0.368 \mathrm{MW}$ and MVAR, respectively.

\section{$4 \quad$ Study cases}

The test system of Fig. 6 is modelled using DIgSILENT Power Factory software, including full dynamic models for DVRs and IMs. An aggregated speed-dependent model for

Table 1 Modelling of heater parameter variations

\begin{tabular}{|l|c|c|c|c|c|}
\hline \multicolumn{1}{|c|}{$C$} & $G$ & $P$ & $P_{\text {disturbance }}$ & $T_{0}$ & $w_{0}$ \\
\hline $\begin{array}{l}\text { normal } \\
\text { distribution }\end{array}$ & $\begin{array}{c}\text { normal } \\
\text { distribution }\end{array}$ & $\begin{array}{c}\text { normal } \\
\text { distribution }\end{array}$ & $\begin{array}{c}\text { white noise and } \\
P_{\text {disturbance }}>0\end{array}$ & $\begin{array}{c}\text { Rand }\left[T_{\text {low, }}\right. \\
\left.T_{\text {high }}\right]\end{array}$ & $\begin{array}{c}\text { randomly chosen, e.g. 30\% } \\
\text { of units initially 'on' }\end{array}$ \\
\hline
\end{tabular}



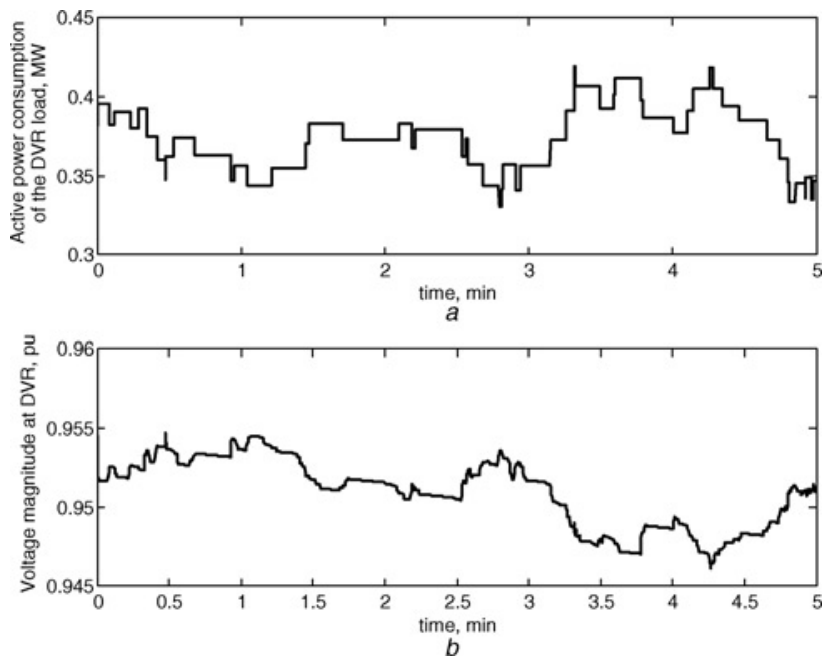

Figure 5 DVR power consumption and voltage profile

a Active power consumption of the DVR model

$b$ Voltage magnitude at the DVR connected bus

the mechanical load was considered, with an exponential coefficient of 1.5 corresponding to a composite system load that varies as a nonlinear function of voltage. Several simulation studies showing the beneficial impact on voltage control and stability from the DVR load are carried out. Simultaneous disconnection of the DVR model is considered, but proportional disconnection will be further

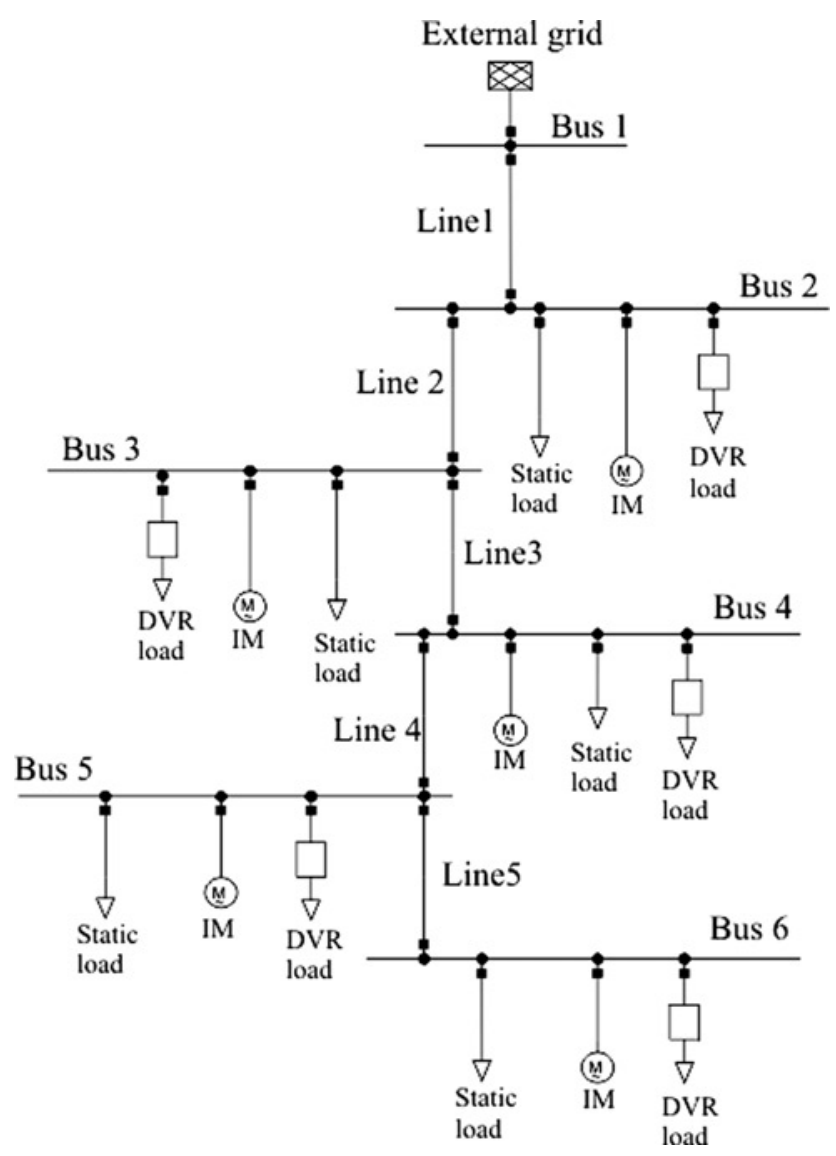

Figure 6 Radial power network
Table 2 Average power consumption of individual loads connected at different buses

\begin{tabular}{|l|l|l|}
\hline & MW & MVAR \\
\hline static load & 0.54 & 0.27 \\
\hline DVR load & 0.37 & 0.37 \\
\hline IM & 0.9 & 0.70 \\
\hline
\end{tabular}

investigated. The IM loading level refers to the total power consumed according to its rated capacity. Table 2 shows the average power consumption of individual loads.

\subsection{Impact of the DVR load on short-term voltage control}

This study was carried out considering a balanced threephase fault (since it represents the most severe case) at Line 5. The performance of the DVR concept is assessed making use of the radial power grid depicted at Fig. 6. It consists of an $11 \mathrm{kV}, 2000 \mathrm{MVA}$ short-circuit level network with six buses. Each bus encompasses aggregated static, DVR and IM load representations, representing approximately 20, 30 and 50\%, respectively, of the total load of the bus. The IM load representation is an aggregated model having in total $1000 \mathrm{~kW}$ of small/ medium IMs on each bus.

Fig. 7 presents a comparison study of the bus voltage magnitude and IM speed deviation with and without DVR action. The solid lines denote system performance when DVR action is taking place, while the dashed lines represent the system without DVR action. The fault duration is $500 \mathrm{~ms}$, and DVR disconnects $30 \%$ of the load after $100 \mathrm{~ms}$ with a voltage below 0.94 p.u. It can be observed that DVR action improves voltage magnitude to its pre-fault value some seconds after the fault is cleared, while without action of the DVR load the bus voltage magnitude does not recover within the simulation period.

Fig. $7 b$ illustrates the behaviour of IM speed during the voltage drop. As can be seen, the re-acceleration of motors is faster when DVR action takes place. A faster voltage recovery implies obtaining a faster electrical torque recovery, which helps to re-accelerate the IMs. It should be remarked that the bus voltage magnitude for the case when DVR is 'off' takes more time to recover to its pre-fault specified value. The depicted simulation period is just for $5 \mathrm{~s}$, while the bus voltage recovers to its pre-fault value for the DVR 'off case in around $10 \mathrm{~s}$. The delay on voltage recovery is due to the longer mechanical transients of the IM and is linked to the active and reactive energy consumption of the IM motor. The magnitude of speed deviation depends mainly on the inertia of motors and the location, type and duration of the fault. But even in severe cases such as the one presented in Fig. 7 (balanced three-phase fault with 

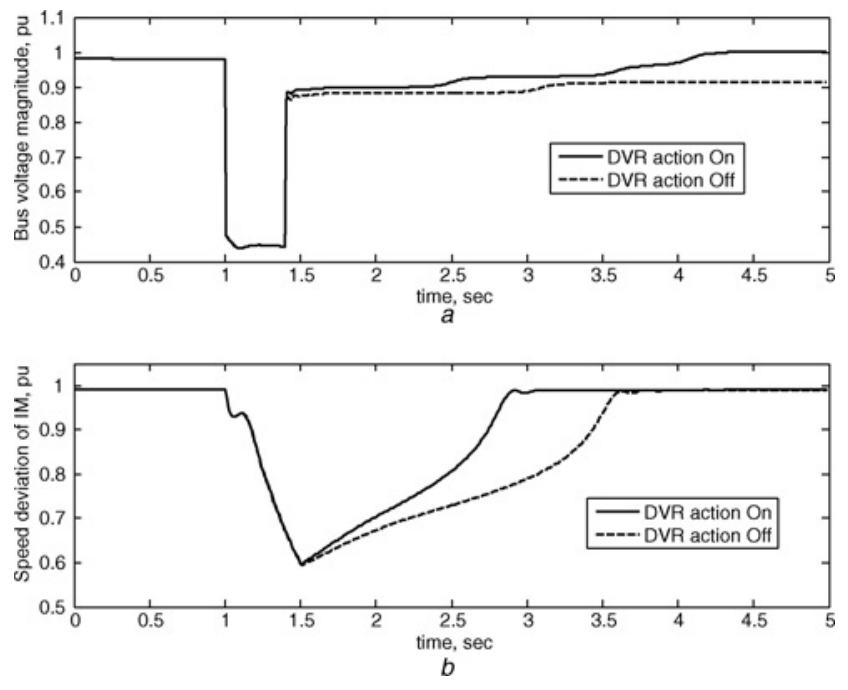

Figure 7 Comparison analyses for on/off DVR performance $a$ Bus voltage magnitudes $b$ IM speed deviation

long duration), DVR could potentially help in preventing the disconnection of loads and the interruption of processes.

Fig. 8 depicts the active and reactive power consumption of the IM during and after the fault is cleared. As can be seen, when DVR is 'on', there is no significant improvement in active power consumption; however, for the reactive power case, the motor requires three times less (over 20 periods) reactive energy to achieve a normal operational condition. This action is directly proportional to temperature rise and overall motor insulation life. Moreover, the inrush current duration will decrease, so the thermal stress on the IM windings will also decreased. After a few seconds, the operation of IMs returns to a normal level as well as the system voltage profile, and DVR loads can be gradually reconnected.
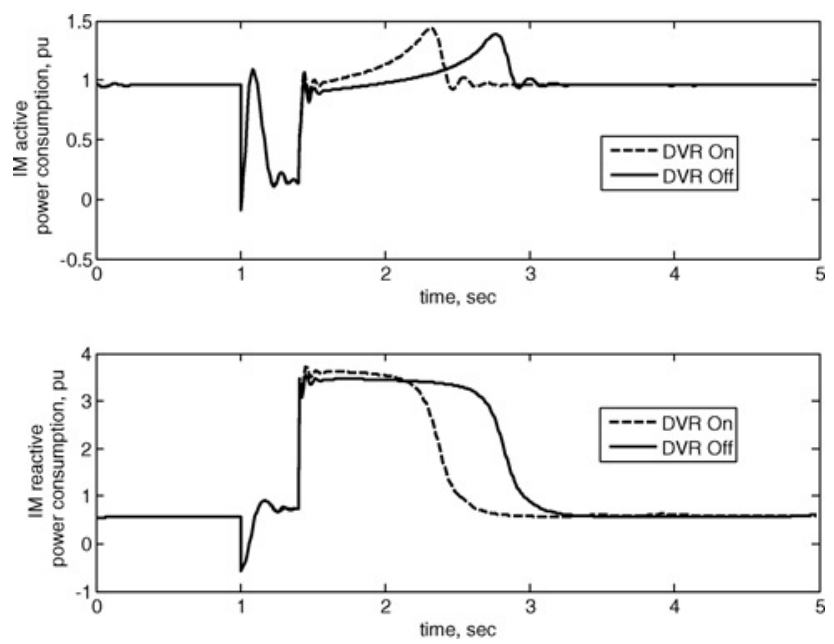

Figure 8 IM active and reactive power consumption for on / off DVR action

\subsection{Impact of DVR load during the start-up of IMs}

The aim of this study is to show the impact of DVR load during the start-up of IMs. The IM attached to bus 6 is connected at time $1 \mathrm{~s}$, while the other IMs are already connected to the grid. Fig. 9 shows the impact of using the DVR load during the start-up of the IM attached to bus 6. As observed, the DVR load supports the voltage magnitude for the IM starting-up period. Moreover, it improves voltage performance and helps the system to recover to the same voltage level as before the connection of the IM. It is noticed that the event of starting up the IM has a detrimental impact on system voltage; however, DVR loads look after the overall system voltage as depicted in Fig. $9 a$, which is the bus voltage magnitude at bus 2. It is observed that due to the IM event, the voltage magnitude at this bus drops to a value close to 0.917 p.u., and around $2 \mathrm{~s}$ later it recovers to a value close to 0.961 p.u. when DVR load is not taking place; however, when DVR load is taking place, the bus voltage magnitude recovers faster and to its pre-fault value. Figs. $9 b$ and $9 c$ show the active and reactive power demand from the IM. As observed, during the start-up period of the IM, there is a high demand for reactive power with the aim of magnetising the air gap, which in turn has an opposite effect on voltage magnitude at the connected bus. Besides there is an increase in active power so as to accelerate the IM to its rated speed. The action of DVR load during this stage improves the voltage magnitude considerably, whereas for the active and reactive power demand of the IM there is also a significant effect reflected on the duration of the starting inrush current, as shown in Fig. 9.

\subsection{Behaviour of DVR load during reconnection}

For this assessment, the general behaviour of the DVR load is analysed. A simulation study is conducted for a total period of 15 mins. At time 1 min a balanced three-phase fault at Line 5 takes place and $400 \mathrm{~ms}$ later it is cleared by primary protection. The DVR load actuates $200 \mathrm{~ms}$ after the fault is applied. Fig. 10 depicts the behaviour of the bus voltage magnitude and the DVR load connected at bus 4 during the whole simulation time. As is noticed, the voltage magnitude remains stable around 1.02 p.u. before the fault is applied; at time $1 \mathrm{~min}$ there is a severe voltage drop to 0.784 p.u. due to the fault that lasts for a small period; then there is an almost instant voltage recovery to a value of 1.025 p.u. due to the fault being cleared and the action of DVR; afterwards the voltage smoothly damps at the end of the simulation to a value of 1.01 p.u. Fig. $10 b$ depicts the behaviour of the active power consumed by the DVR load for the simulation period. The random behaviour of the DVR load is clearly observed, as it will be for a real-life demand. DVR load consumption varies around $0.4 \mathrm{MW}$ before the fault is applied, but during the fault all of the DVR load consumption is fully disconnected in order to improve the voltage magnitude of the system and prevent further 

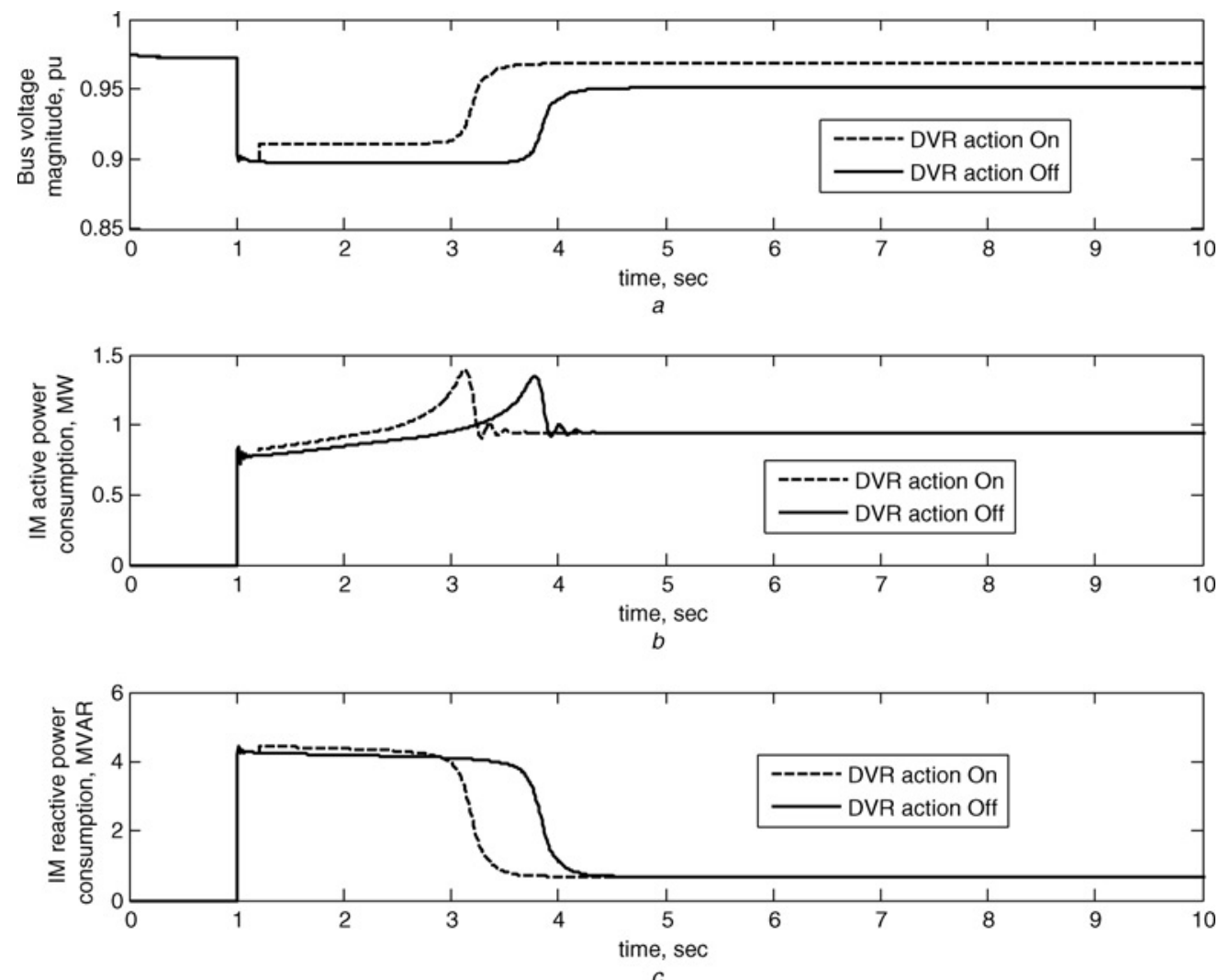

Figure 9 Impact of DVR during the start-up of the IM

$a$ Voltage magnitude

$b$ IM active power consumption

c IM reactive power consumption connected at bus 6

instabilities in the network. Next the DVR load is reconnected gradually in order to prevent further voltage fluctuations. Moreover, the nature of the DVR load does not allow full reconnection because it actuates according to its preliminary temperature and voltage settings, as previously explained in
Section 3. After the voltage level is recovered to 0.95 p.u. and considering a time delay of $4 \mathrm{~min}$, the temperature control is again prioritised and gradually reconnects the loads as the limit temperature of each individual appliance is reached. It should be emphasised that control logics such as

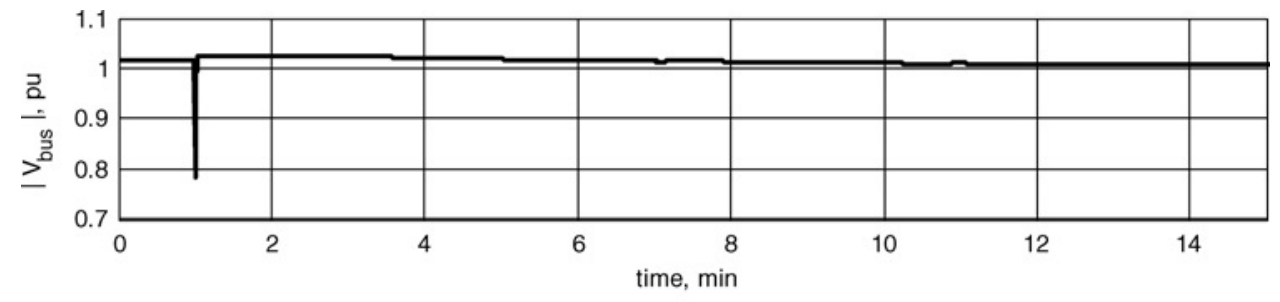

a

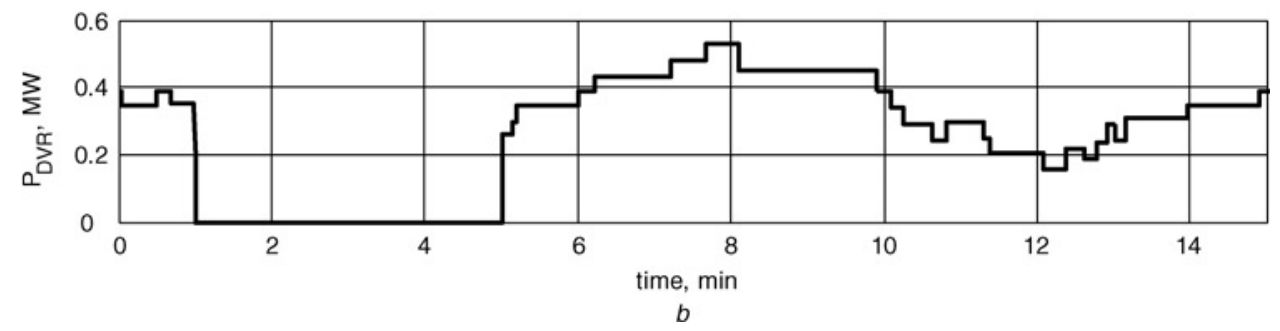

Figure 10 Voltage and power behaviour for a $10 \mathrm{sec}$ simulation period

$a$ Voltage magnitude at bus 4

$b$ Active power consumption of DVR load 
those applied for DVR loads may create a return power after the voltage of the system is recovered. As can be seen in Fig. $10 b$, from 1 to $5 \mathrm{mins}, 100 \%$ of the appliances are disconnected. This means that the temperature of all appliances will move in the same direction during the fault, reaching after a certain time the highest/lowest temperature limit, depending on the type of coolers/heaters. The result is that there is no simultaneous reconnection of having close to $100 \%$ of the appliances 'on' after the fault, avoiding over reaction from the DVR load. By the end of the simulation test case, DVR load model has already been recovered to a normal random behaviour as before the fault was applied.

\section{Conclusions and future work}

This paper introduces the concept of 'demand as VCR'. The idea proposes that certain loads of typical distribution systems could be controlled with the objective of improving system stability and performance in the short term.

A comprehensive DVR model was developed, which was demonstrated to be an effective load control tool to alleviate voltage recovery. A detailed design and mathematical modelling section is presented and several test cases with different scenarios are carried out.

In a nutshell, this paper establishes an alternative and innovative demand side solution for short-term voltage control, which could be complementary to traditional techniques. This technology controls some thermal dynamic loads where the impact of their disconnection for a short period is irrelevant, in terms of disturbing a customer's comfort or influencing industrial processes. The key idea is to use the already existing resources from the demand side to improve voltage system performance. DVR technology can be seen as a distributed means for voltage support at a lower cost in comparison with conventional solutions. It represents a smarter way to use the existing facilities rather than installing new, costly and environmentally polluting equipments; making this solution an efficient and feasible scheme to implement.

Our current work only addresses some of the key issues related to smart demand side management for short-term voltage control; more follow-up research is needed to improve the proposed method for eventual widespread use.

Our next research effort will focus on the following two aspects:

- Extend the proposed technique to encompass wind generation in areas with a high penetration of traditional Danish concept wind turbines to evaluate its interaction during short-term voltage fluctuations.

- In the long run, there is a need to investigate the DVR concept for long-term voltage control in case of severe operation conditions, to avoid blackouts and voltage collapse. Develop concepts necessary to design, implement and test DVR for this purpose while considering coordination with other functions, such as DFR for frequency control and DVR for short-term voltage control.

\section{References}

[1] KUNDUR P.: 'Power system stability and control' (McGraw-Hill, 1994)

[2] TAYLOR C.W.: 'Power system voltage stability' (McGrawHill, 1994)

[3] CARTWRight P., hOldSWORTH L., EKANAYABE J.B., JenkinS N.: 'Coordinated voltage control strategy for a doubly-fed induction generator (DFIG)-based wind farm', IEE Gener. Trans. Distrib., 2004, 151, (4), pp. 495-502

[4] VISWANADHA RAJU G.K., BIJWE P.R.: 'Reactive power/voltage control in distribution systems under uncertain environment', IET Gener. Trans. Distrib., 2008, 5, (2), pp. 752-763

[5] EL MOURSI M., JOOS G., ABBEY C.: 'A secondary voltage control strategy for transmission level interconnection of wind generation', IEEE Trans. Power Electron., 2008, 23, (3), pp. 1178-1190

[6] VIAWAN F.A., KARLSSON D.: 'Voltage and reactive power control in systems with synchronous machine-based distributed generation', IEEE Trans. Power Deliv., 2008, 23, (2), pp. 1079-1087

[7] EL MOURSI M., JOOS G., ABBEY C.: 'High-performance voltage control scheme for wind park integration', IET Renew. Power Gener., 2007, 1, (3), pp. 151-159

[8] FU X., WANG X.: 'Unified preventive control approach considering voltage instability and thermal overload', IET Gener. Trans. Distrib., 2007, 1, (6), pp. $864-871$

[9] Miguelez L., CEREZO F.M.E., ROUCO L.: 'On the assignment of voltage control ancillary service of generators in Spain', IEEE Trans. Power Syst., 2007, 22, (1), pp. 367-375

[10] NOGUCHI S., PASERBA J.: 'Improvement to an advance high side voltage control', IEEE Trans. Power Syst., 2006, 21, (2), pp. 683-692

[11] MARCUS-M $\varnothing L L E R$ C.: 'Demand as frequency controlled reserve - analysis of technology and potentials'. B.Sc. thesis, Technical University of Denmark, 2006

[12] XU Z., ØSTERGAARD J., TOGEBY M., MARCUS-M $\varnothing L L E R$ C.: 'Design and modelling of thermostatically controlled loads as frequency controlled reserve'. IEEE General Meeting, Power Engineering Society, June 2007, pp. 1-6 
[13] SHORT J.A., INFIELD D.G., FRERIS L.L.: 'Stabilization of grid frequency through dynamic demand control', IEEE Trans. Power Syst., 2007, 22, (2), pp. 1284-1293

[14] Pacific Northwest National Laboratory: 'Grid friendly controller helps balance energy supply and demand', 2002 [Online]. Available http://www.pnl.gov/

[15] HALPIN S.M., HARLEY K.A., JONES R.A., TAYLOR L.Y.: 'Slopepermissive under-voltage load shed relay for delayed voltage recovery mitigation', IEEE Trans. Power Syst., 2008, 23, (3), pp. 1211-1216

[16] IEEE Load Task Force on Load representation for dynamic performance, RICE W.W (CHAIRMAN), 'Load representation for dynamic performance studies', IEEE Trans. Power Syst., 1993, 8, (2), pp. 472-482

[17] GREWAL G.S., POCSAI S., HAKIM M.M.: 'Transient motor reacceleration study in an integrated petrochemical facility', IEEE Trans. Ind. Appl., 1999, 35, (4), pp. 968-977

[18] DAS J.C.: 'Effect of momentary voltage dips on the operation of induction and synchronous motors', IEEE Trans. Ind. Appl., 1990, 26, (4), pp. 711-718
[19] GOMEZ J.C., MORCOS M.M., REINERI C.A., CAMPETELLI G.N.: 'Behaviour of induction motor due voltage sags and short interruptions', IEEE Trans. Power Deliv., 2002, 17, (2), pp. $434-440$

[20] GOMEZ J.C., MORCOS M.M., REINERI C.A., CAMPETELLI G.N.: 'Behaviour of induction motor protection due voltage sags and short interruptions', IEEE Power Eng. Rev., 2001, 21, (11), pp. 62-62

[21] IEEE Standards: 'IEEE Recommended practice for monitoring electric power quality', 1995, pp. 1159-1195

[22] NERC: 'Reliability standards for the bulk electric systems of North America', 2007 [Online]. Available: http://www.nerc.com/ (accessed April 2009)

[23] Nordel: 'Nordic grid code', 2007 [Online]. Available: http://www.nordel.org/ (accessed April 2009)

[24] UCTE: 'Operation handbook', 2008 [Online]. Available: http://www.ucte.org/ (accessed April 2009)

[25] National Grid Electricity Transmission: 'The grid code', 2008 [Online]. Available: http://www.nationalgrid.com/ (accessed April 2009) 